\title{
Shear strengthening of reinforced concrete beams with near surface mounted steel bars
}

\author{
Rendy Thamrin ${ }^{1, *}$, Sabril Haris ${ }^{1}$, and Zaidir $^{1}$ \\ ${ }^{1}$ Department of Civil Engineering, Universitas Andalas, Padang, Indonesia
}

\begin{abstract}
This paper reports on an experimental study examining reinforced concrete beams without stirrups strengthened with Near Surface Mounted (NSM) steel bars. The beams were simply supported and were subjected to four point bending load. Three beams tested were designed as control specimens and the other six beams were strengthened with NSM steel bars. Three ratios of longitudinal reinforcement $(1 \%, 1.4 \%$, and $2.4 \%)$ and two types of installation angle (45 and 90 degree) were used as test variables. The test results in terms of graphs of deflection due to shear forces are presented to demonstrate the ability of different longitudinal reinforcement ratios and installation angle to withstand shear forces. The influence of the test variables on the crack patterns was also observed. It was found that NSM steel bars increase the shear strength of reinforced concrete beams without stirrups significantly. However, in the case of higher longitudinal reinforcement ratios the beams failed in brittle mode as indicated by a sudden drop in the shear force-deflection graphs.
\end{abstract}

\section{Introduction}

The use of NSM in the rehabilitation and strengthening of existing damaged concrete structures has been becoming popular in the last decade [1-5]. Besides being simple and economical, this method also has a quick installation time. CFRP and GFRP bars are the most commonly used reinforcing materials for NSM [1-4]. However, the prices of FRP materials are still high compared to ordinary steel reinforcements and plates.

Increasing the shear capacity of reinforced concrete members by using epoxy resins and steel reinforcements has been used for the past three decades. The efficacy of application of epoxy resins for shear strengthening of pre-cracked reinforced concrete beams with stirrups to increase the shear strength has been observed experimentally in the author's previous study [6]. In this study, the shear cracks were injected with epoxy resins using a sealant injection method. The test result showed that the injection of epoxy resin with a sealant injection method was effective in restoring the shear strength of damaged reinforced concrete beams.

Previous studies carried out by the other researchers [1, 4] have reported that NSM FRP bars increase the shear capacity of reinforced concrete beams without and with steel stirrups. The test results from their studies also indicated that debonding failure of FRP rods

${ }^{*}$ Corresponding author: rendythamrin@gmail.com 
occurred and a longer bond length was suggested to avoid this type of failure. However, this new arrangement, with longer bond length, may lead to debonding failure with concrete cover delamination.

The reports discussed in the literature above confirm that the use of NSM FRP bars is increasing fast. However, it is the concern of the authors that this method is inappropriate in the developing world where funds for reconstruction are often severely limited. The number of experimental studies evaluating the shear capacity with NSM cheaper steel bars is still inadequate. Therefore, the purpose of this study is to investigate experimentally the shear capacity of reinforced concrete beams strengthened with NSM steel bars.

\section{Experimental study}

Nine simply supported reinforced concrete beams without stirrups, consisting of three control beams and six beams strengthened with NSM steel bars were prepared and tested. The beam cross-section had dimensions of $125 \mathrm{~mm}$ width and $250 \mathrm{~mm}$ height. The shear span length was $800 \mathrm{~mm}$, and the distance between the two point loads was $400 \mathrm{~mm}$. The anchorage length beyond the support was $150 \mathrm{~mm}$. Fig. 1 shows a schematic view of the beam's dimension, beam's cross-section, and load position.

(a) Control beams (BCS-01, BCS-02, BCS-03).

(b) Vertical (90 degree) application of NSM steel bars $(\mathrm{BN}-01 \mathrm{~V}, \mathrm{BN}-02 \mathrm{~V}, \mathrm{BN}-03 \mathrm{~V})$.

(c) Diagonal (45 degree) application of NSM steel bars (BN-01D, BN-02D, BN-03D).

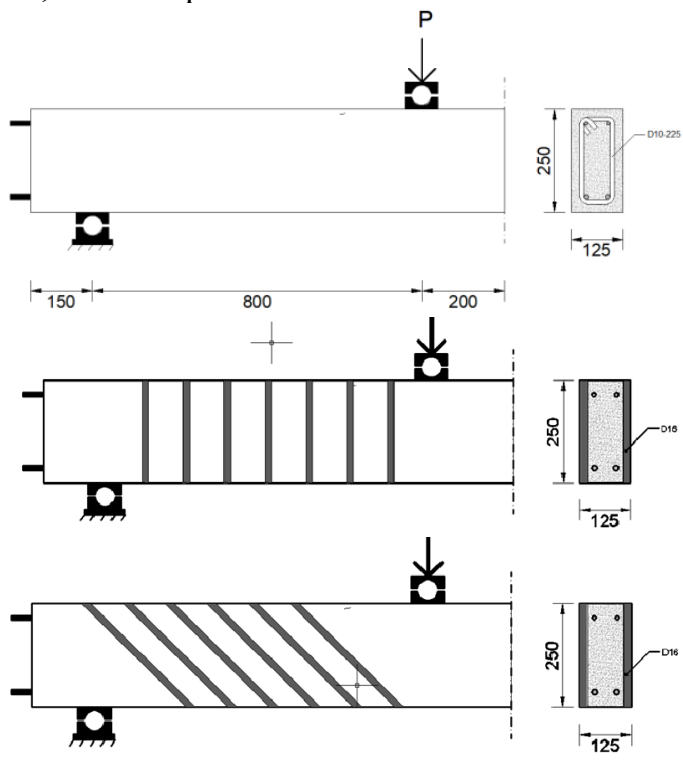

Fig. 1. Dimensions, loading position, and NSM steel bars schemes of the tested beams.

The longitudinal tension reinforcement used was deformed steel bars with a diameter of $13 \mathrm{~mm}$ and yield strength of $448 \mathrm{MPa}$. The longitudinal compression reinforcement was deformed steel bars with a diameter of $10 \mathrm{~mm}$ and yield strength of $355 \mathrm{MPa}$. Ready mix commercial concrete with the maximum aggregate size of $10 \mathrm{~mm}$ was used. The average concrete compressive strength obtained from compression tests after 28 days curing time was $20 \mathrm{MPa}$.

Beams strengthened with NSM steel bars had groove cuts initially arranged inside the formwork using wooden bars before pouring fresh concrete into the formwork of the beam. The formwork was released after 28 days of curing. Then, the groove surfaces were cleaned to take out fine particles and dust. The grooves were filled halfway with epoxy adhesive using a palette knife before inserting the steel bars. The steel bars $(16 \mathrm{~mm}$ diameter and 355 MPa yield strength) were immediately placed inside the grooves and pressed lightly along 
the plate to the adhesive. The grooves were finally filled with epoxy adhesive paste, and the surface was leveled as illustrated in Fig 2.
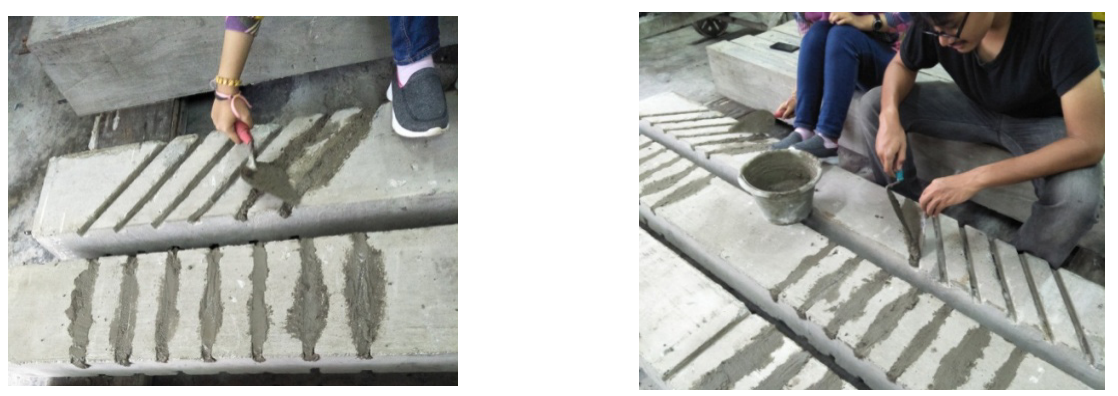

Fig. 2. The installation process of NSM steel bars.

\section{Theoretical flexural and shear strength}

An analytical study based on cross-section analysis [7-9] was applied to obtain theoretical flexural strength. In this method, the cross section of the reinforced concrete is divided into a finite number of concrete and reinforcement layers. The stress-strain relationship of concrete in compression used in this study is adopted from literature [10]. The stress-strain relationship of concrete in tension used is linear up to the tensile strength without tension stiffening. The stress-strain model for steel bars employed in this study is bi-linear. The analytical load-deflection relationship is obtained from the moment-curvature distribution.

The theoretical nominal shear strength of the beams was obtained using the equation provided by ACI 318M-14 [11] as:

$$
\begin{gathered}
V_{c}=0.172 \lambda \sqrt{f_{c}^{\prime}} b_{w} d \\
V_{s}=\frac{A_{v} f_{y t}(\sin \alpha+\cos \alpha) d}{s} \\
\phi V_{n}=\phi\left(V_{c}+V_{s}\right)
\end{gathered}
$$

where $f_{c}{ }^{\prime}$ is the concrete compressive strength, $\lambda$ is the modification factor to reflect the reduced mechanical properties of lightweight concrete, $b w$ is the width of the web, $d$ is the effective depth, $A_{v}$ is the area of NSM steel bars, $\alpha$ is the angle of application of NSM steel bars direction, $s$ is the center-to-center spacing of NSM steel bars. The test results and the calculated theoretical flexural and shear capacities of the beams are listed in Table 1.

\section{Results and discussion}

The results of the experimental study in term of shear force versus mid-span deflection curves for all of the beams are shown in Fig. 3. The load level related to the first flexural crack for all the tested beams was at an average value of $12 \mathrm{kN}$. All of the control beams failed in shear as a result of the formation of the diagonal shear cracks in the shear span zone. The diagonal shear crack loads were developed at an average value of $24 \mathrm{kN}$. This level of load is higher than theoretical nominal concrete shear strength $\left(V_{c}\right)$ obtained using Eq. 1 with a strength reduction factor of 0.75 .

The beams strengthened with NSM steel bars failed in flexural (BN-01D, BN-02D, BN$01 \mathrm{~V}$, and $\mathrm{BN}-02 \mathrm{~V})$ and shear $(\mathrm{BN}-03 \mathrm{D}$ and $\mathrm{BN}-03 \mathrm{~V})$ failures. It is shown in Fig. 3 that 
NSM steel bars significantly increase the shear capacity of the beams. However, two of the beams with NSM steel bars did not reach the ultimate flexural capacity due to the occurrence of shear failure. This type of failure is indicated by the sudden drop of strength in the experimental load-deflection curves. The nominal shear capacities of the strengthened beams obtained using Eq. 2 and 3 are listed in Table 1.

Table 1. Beam data and capacities.

\begin{tabular}{|c|c|c|c|c|c|c|c|c|c|c|c|c|c|c|c|c|}
\hline \multirow{3}{*}{ Specimens } & \multicolumn{5}{|c|}{ NSM Steel Bars } & \multicolumn{3}{|c|}{$\begin{array}{l}\text { Longitudinal } \\
\text { Reinforcement } \\
\text { (Tension) }\end{array}$} & \multicolumn{3}{|c|}{$\begin{array}{c}\text { Longitudinal } \\
\text { Reinforcement } \\
\text { (Compression) }\end{array}$} & \multicolumn{3}{|c|}{ ACI $318-14$} & \multirow{2}{*}{$\begin{array}{c}\text { Exp. } \\
\text { Shear } \\
\text { Strength } \\
\text { Vu exp. }\end{array}$} & \multirow{2}{*}{\begin{tabular}{|c} 
Calc. \\
Flexural \\
Capacity \\
$V b$
\end{tabular}} \\
\hline & & $d$ & $s$ & fyt & & & $d_{1}$ & & & $d_{h}$ & & $V c$ & $V s$ & $V n$ & & \\
\hline & $\left(\mathrm{mm}^{2}\right)$ & $(\mathrm{mm})$ & $(\mathrm{mm})$ & (MPa) & $\alpha$ & $\mathrm{N}$ & $(\mathrm{mm})$ & $\rho(\%)$ & $\mathrm{N}$ & $(\mathrm{mm})$ & $\rho^{\prime}(\%)$ & $(\mathrm{kN})$ & $(\mathrm{kN})$ & $(\mathrm{kN})$ & $(\mathrm{kN})$ & $(\mathrm{kN})$ \\
\hline BCS-01 & & & & & & 2 & & 1.0 & & & & & 0.0 & 15.4 & 22.2 & 30 \\
\hline BCS-02 & & & & & & 3 & & 1.4 & & & & & 0.0 & 15.4 & 24.4 & 43 \\
\hline BCS- 03 & & & & & & 5 & & 2.4 & & & & & 0.0 & 15.4 & 26.4 & 58 \\
\hline BN-01V & 402.1 & 220.0 & 100.0 & 476.2 & 90.0 & 2 & & 1.0 & & & & & 418.4 & 329.2 & 35.0 & 30 \\
\hline BN-02V & 402.1 & 220.0 & 100.0 & 476.2 & 90.0 & 3 & 13.0 & 1.4 & 2 & 10.0 & 0.6 & 20.5 & 418.4 & 329.2 & 46.0 & 43 \\
\hline $\mathrm{BN}-03 \mathrm{~V}$ & 402.1 & 220.0 & 100.0 & 476.2 & 90.0 & 5 & & 2.4 & & & & & 418.4 & 329.2 & 66.0 & 58 \\
\hline BN-01D & 402.1 & 220.0 & 100.0 & 476.2 & 45.0 & 2 & & 1.0 & & & & & 594.8 & 461.4 & 34.0 & 30 \\
\hline BN-02D & 402.1 & 220.0 & 100.0 & 476.2 & 45.0 & 3 & & 1.4 & & & & & 594.8 & 461.4 & 48.0 & 43 \\
\hline BN-03D & 402.1 & 220.0 & 100.0 & 476.2 & 45.0 & 5 & & 2.4 & & & & & 594.8 & 461.4 & 54.0 & 58 \\
\hline
\end{tabular}

Fig. 4 shows the comparison of the test results with theoretical flexural capacities $\left(V_{b}\right)$. It is shown that theoretical flexural capacities $\left(V_{b}\right)$ compare well with the test results. These theoretical flexural capacities also confirm that the beams with NSM steel bars reach the flexural capacities except for beams BN-03D and BN-03V. Even though the load-deflection curve of BN-03D indicates yielding of tensile longitudinal reinforcement, which is also in agreement with the load-deflection curve obtained from flexural analysis, this beam exhibited shear failure before the beam reached the theoretical ultimate flexural capacity.

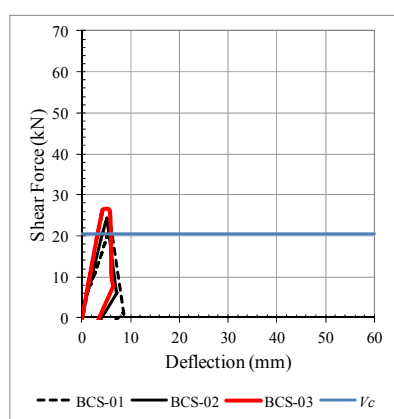

(a) Control beams.

Fig. 3. Shear force versus mid-span deflection of the tested beams.

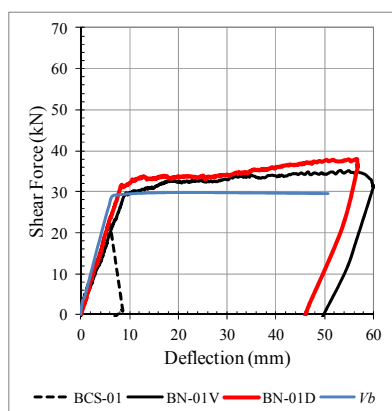

(a) Reinforcement ratio $1.0 \%$.

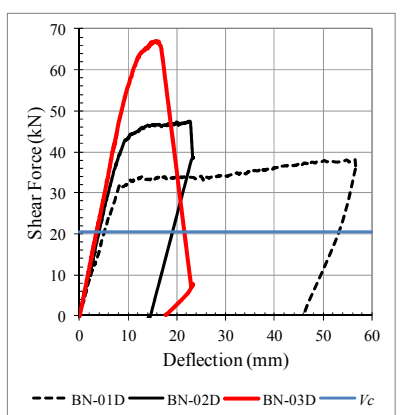

(b) Diagonal application.

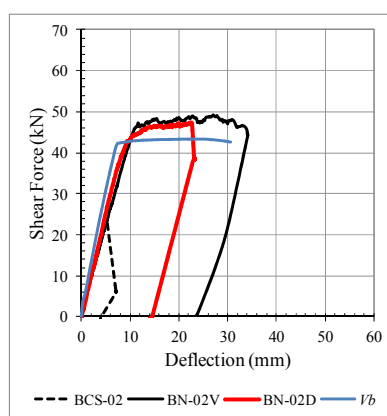

(b) Reinforcement ratio $1.4 \%$.

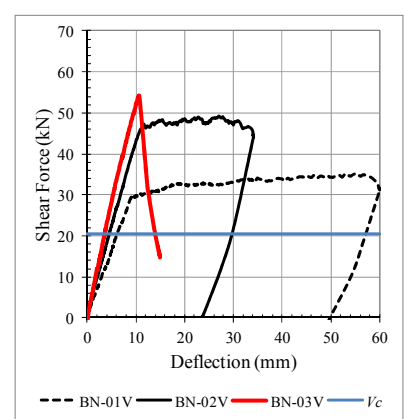

(c) Vertical application.

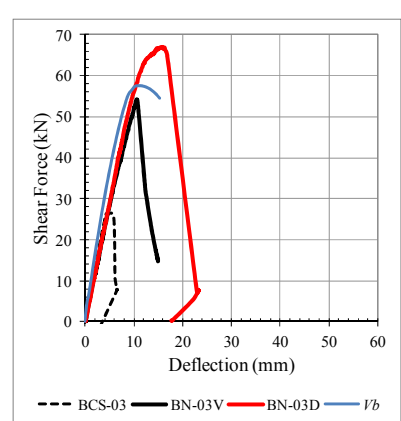

(c) Reinforcement ratio $2.4 \%$. 
Fig. 4. Comparison of the test results with theoretical flexural capacities.

(a) BCS-01

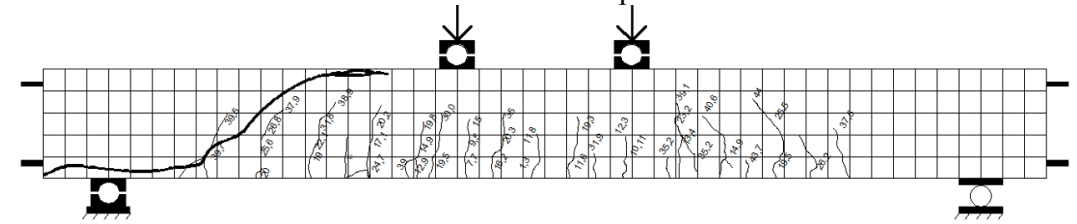

(b) BCS-02

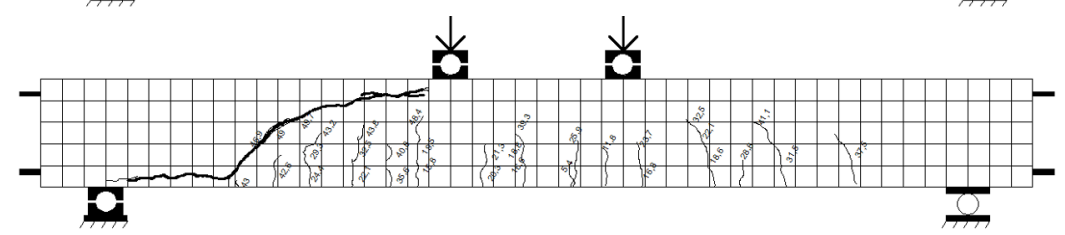

(c) BCS-03

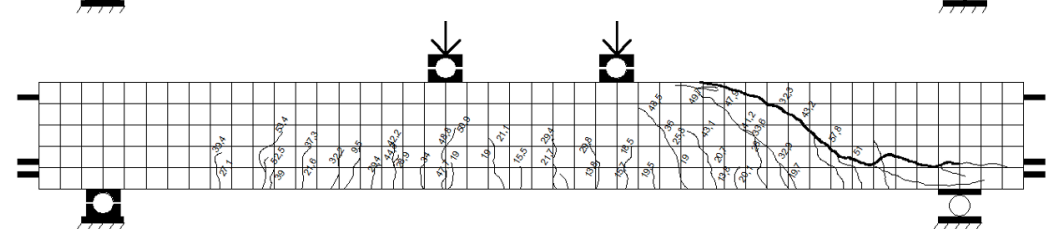

(d) $\mathrm{BN}-01 \mathrm{~V}$

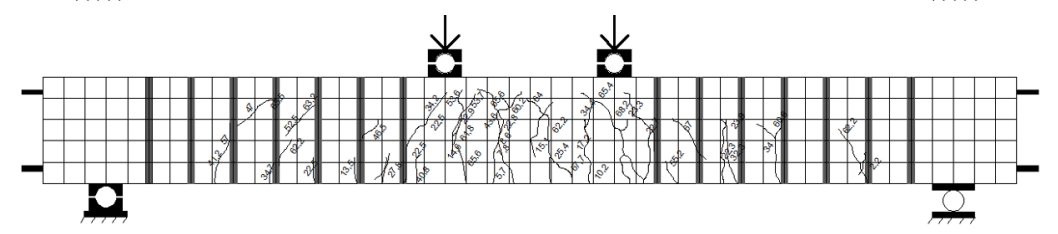

(e) $\mathrm{BN}-02 \mathrm{~V}$

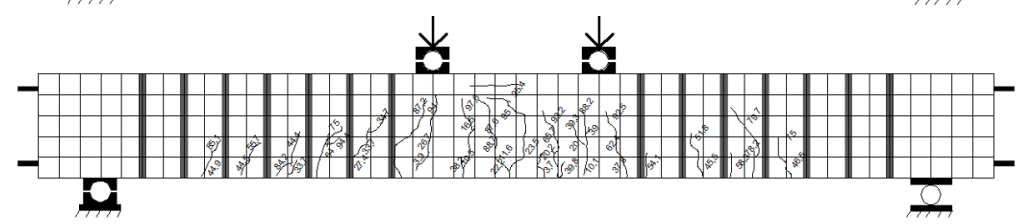

(f) $\mathrm{BN}-03 \mathrm{~V}$

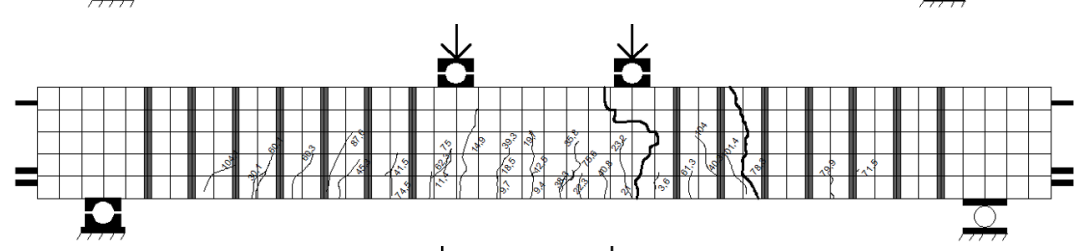

(g) BN-01D

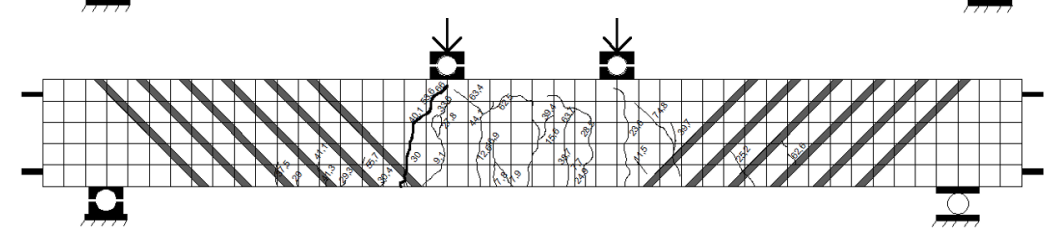

(h) BN-02D

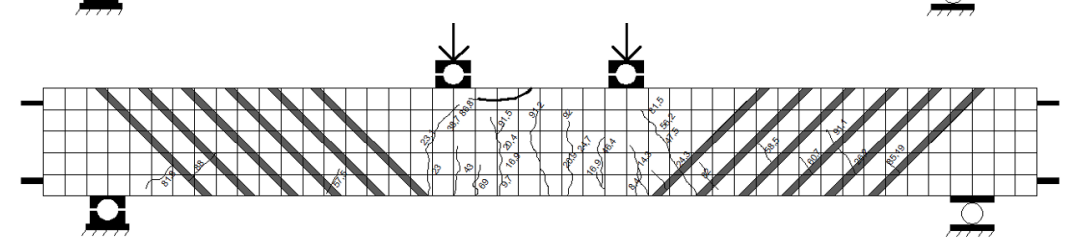

(i) $\mathrm{BN}-03 \mathrm{D}$

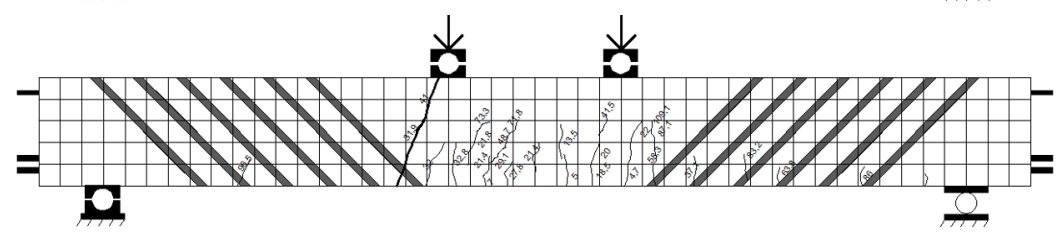

Fig. 5. Failure modes and cracking patterns of the tested beams. 
The crack patterns of the tested beams are illustrated in Fig. 5. In case of control beams, it is shown that the flexural cracks spread along the tensile zone before the sudden failure caused by the propagation of the diagonal shear cracks. Meanwhile, the constant moment zone of the strengthened beams is severely cracked due to the installation of NSM steel bars. This indicates that the installation of NSM steel bars significantly influenced the crack patterns of the beams.

\section{Conclusions}

The conclusions can be drawn as follows. All of the control beams failed in shear failure as indicated by a sharp decrease in the capacity of load-deflection curves.nA strengthening method using NSM with steel bars increases the shear capacity of the strengthened beams significantly. The strengthened beams with reinforcement ratio of $1 \%$ and $1.4 \%$ reached flexural capacity as confirmed by load-deflection curves obtained from analytical results.

The author would also like to thank LPPM of Andalas University for the research fund support through Penelitian Skim Klaster Riset Guru Besar with contract number 22/UN.16.17/PP.RGBL/ LPPM/2018 in the financial year 2018.

\section{References}

1. L.D. Lorenzis, A. Nanni, ACI Structural Journal 98, 1 (2001)

2. R. El-Hacha, S.H. Rizkalla, ACI Structural Journal 101, 5 (2004)

3. Z.K. Szabó, G.L. Balázs, Periodica Polytechnica Civil Engineering 51, 1 (2007)

4. P. Sabol, S. Priganc, Procedia Engineering 65 (2013)

5. A. Parvin, T.S. Shah, Journal of Polymers 8 (2016)

6. Zaidir, R. Thamrin, E. Dalmantias, Int. J. on Adv. Science Eng. Information Tech. 7, 2 (2017)

7. R. Park, T. Paulay, Reinforced concrete structures (John Wiley, New York, 1975)

8. R. Thamrin, MATEC Web of Conf. 103 (2017)

9. R. Thamrin, R.P. Sari, Procedia Engineering 171 (2017)

10. J.B. Mander, M.J.N. Priestley, R. Park, J.1 of Structural Engineering 114, 8 (1988)

11. ACI, Building Code Requirements for Structural Concrete ACI 318-14 (American Concrete Institute, Farmington Hill, 2014) 